\title{
DISCURSOS DA AVALIAÇÃO ESCOLAR NA CONTEMPORANEIDADE
}

\author{
Sônia Regina da Luz Matos' \\ Betina Schuler2
}

\section{RESUMO}

Este artigo problematiza os discursos da avaliação escolar, em suas relações com as sociedades disciplinar e de controle. A partir de uma perspectiva pós-estruturalista em educação, examinamos os programas da disciplina de Avaliação em um curso de Pedagogia de uma instituição de Ensino Superior no sul do Brasil, buscando rastrear os conceitos e bibliografias operados nesses materiais. Retiramos desses programas, os elementos de normalização que produzem padrões e formam saberes que constituem um tipo de vontade de verdade sobre o tema. Identificamos, a partir de tal exame, o discurso da avaliação classificatória e o discurso da avaliação crítica, buscando problematizar seus efeitos de poder e saber.

Palavras-chave: Avaliação Escolar. Discurso. Poder. Saber.

\section{DISCOURSES OF EVALUATION AT SCHOOL IN THE PRESENT}

\begin{abstract}
This article problematizes the school evaluation discourses in their relations with the disciplinary and control societies. Based on a post-structuralist perspective on education, we have examined the programs of the discipline of Evaluation in an undergraduate Pedagogy course in a Higher Education institution in the south of Brazil, aiming at charting concepts and references operated in these materials. We have also highlighted the elements of normalization that both produce patterns and formulate knowledges that constitute a kind of will of truth on evaluation. Based on this exam, we have identified the discourse of classificatory evaluation and the discourse of critical evaluation, in an attempt to problematize its effects of power and knowledge.
\end{abstract}

Keywords: School Evaluation. Discourse. Power. Knowledge.

\footnotetext{
1 Doutora Cotutela em Educação pela Universidade Federal do Rio Grande do Sul (UFRGS) e Sciences de IEducation (Université Lumière Lyon 2). Pós-Doutorado pela Université Paris 10 Nanterre, Laboratório de Pesquisa Filosofia, Arte e Estética. Professora no Centro de Humanidades e no Programa de Pós-Graduação em Educação da Universidade de Caxias do Sul (UCS), Caxias do SUI/RS. E-mail: sonia_matos@bol.com.br

2 Doutora em Educação pela Pontifícia Universidade Católica do Rio Grande do Sul (PUCRS). Pós-Doutorado em Educação pela Universidade de Lisboa. Pós-Doutorado em Ciências Humanas pela Griffith University. Escola de Humanidades e Professora Permanente do Programa de Pós-Graduação em Educação da Universidade do Vale do Rio dos Sinos (UNISINOS), São Leopoldo/RS. E-mail: beschuler@unisinos.br
} 


\section{DISCURSOS DE LA EVALUACIÓN ESCOLAR EN LA CONTEMPORANEIDAD}

\section{RESUMEN}

Este artículo problematiza los discursos de la evaluación escolar en sus relaciones con las sociedades disciplinarias y de control. Desde una perspectiva postestructuralista en educación, examina los programas de la disciplina de Evaluación en un curso de Pedagogía de una institución de Enseñanza Superior en el sur de Brasil, buscando rastrear los conceptos y bibliografías operadas en esos materiales. Hemos retirado de esos programas los elementos de normalización que producen patrones y forman saberes que constituyen un tipo de voluntad de verdad sobre el tema. Reconocemos, a partir de tal examen, el discurso de la evaluación clasificatoria y el discurso de la evaluación crítica, buscando problematizar sus efectos de poder y saber.

Palabras clave: Evaluación Escolar. Discurso. Poder. Saber.

\section{ARQUITETANDO UMA CONSTRUÇÃO ENTRE SOCIEDADE, CURRÍCULO E AVALIAÇÃO}

Apontamos neste texto, discursos da avaliação escolar em suas relações com os funcionamentos das sociedades disciplinar e de controle. Para tanto, iniciamos descrevendo um trecho do conto do autor Kafka (2002a), especificamente o texto Durante a construção da muralha da China. O autor tcheco expõe o leitor a uma construção, sem começo, nem fim, na qual tudo gira em torno da edificação de uma muralha, levando-nos a pensar sobre os funcionamentos da sociedade disciplinar, que ainda nos atravessa no século XXI, mas com vestígios e acoplamentos de uma sociedade de controle, ramificada na contemporaneidade. Retiramos desse texto, um excerto para desencadear nossa afirmação de que os funcionamentos das sociedades disciplinar e de controle produzem discursos sobre a escola e sobre os modos de operacionalização do sistema de avaliação.

A muralha da China foi terminada no seu trecho mais setentrional [...] Sem dúvidas devem existir brechas que não foram absolutamente cobertas - para muitos, bem maiores que as partes construídas [...]. Lembro-me ainda muito bem quando nós, crianças pequenas, mal seguras das nossas pernas, ficávamos no jardinzinho do nosso mestre e precisávamos construir uma espécie de muralha com seixos, e como o mestre, a túnica arregaçada, corria de encontro à muralha, naturalmente deitava tudo por terra e nos fazia tais censuras por 
causa da fragilidade de nossa construção, que nós saíamos berrando por todos os lados em busca de nossos pais. Um incidente minúsculo, mas significativo para o espírito da época. Tive sorte de aos vinte anos ser aprovado na prova máxima da escola de nível superior exatamente quando começou a construção da muralha. Digo sorte porque muitos dos que haviam alcançado antes o grau mais elevado da formação que Ihes era acessível, anos a fio não sabiam o que fazer com o seu conhecimento e, a cabeça cheia de planos de construção mais grandiosos, andavam de lá para cá inutilmente, desmoralizando-se aos montes (KAFKA, 2002a, p.72-76).

Pode-se dizer que o autor prefigura os séculos de muros. Séculos de muralhas de seixos. Séculos de planos das construções. Séculos das provas escolares. Séculos em que não se concluiu a construção prometida. Mas como funciona a construção, mesmo que seja a partir da muralha de seixos, do jardinzinho com nosso mestre?

O conto é entendido como um sintoma de como produzimos o funcionamento das sociedades e de como elas atravessam as nossas construções entre os séculos XX e XXI. Os valores aí valorados estão nas histórias contadas e nas não ditas, nas construções que inventamos para habitar, nos movimentos religiosos e científicos que escolhemos para crer, nos jogos de verdade das sociedades que nos habitam. Também avistamos as construções dimensionadas no programa Google, que, atualizado no espaço Earth, nos faz examinar e visitar outras formas de existir. Podemos pensar de outros modos essa construção? O mais relevante nas construções é o que nos responde Kafka (2002a, p. 76): "sem dúvidas devem existir brechas que não foram absolutamente cobertas - para muitos, bem maiores que as partes construídas", uma resposta dada apostando nas brechas produzidas.

Com esse entendimento, o presente texto apresenta o resultado de nossa pesquisa junto ao Observatório de Educação desenvolvida na instituição onde pesquisamos. A investigação é produzida pela emergência do presente que se faz nas ramificações das sociedades e examina alguns discursos produzidos nos programas da disciplina de Avaliação do curso de Pedagogia, de uma universidade da região sul do Brasil. Para tanto, somente os programas dos cursos presenciais foram investigados, e deles extraímos os 
dados bibliográficos e conceituais a partir da Proposta Curricular, no período entre 2010 e 2014.

A pesquisa mostra algumas narrativas vigentes sobre o tema e como elas se compõem com a construção das sociedades. Perguntávamo-nos: quando os profissionais da educação fazem seus programas curriculares e disciplinares, estariam presos a quais muralhas? Que seixos operam nas suas construções e brechas curriculares quando se trata do tema avaliação?

A construção da instituição escolar e a sistematização da avaliação foram produções curriculares elaboradas nas sociedades de pensamento moderno. Tal pensamento produziu uma variedade de formas de existir em sociedade, nas escolas, nas universidades.

Aqui priorizamos o recorte filosófico para tratar das produções das sociedades e da dinâmica curricular sobre o tema avaliação. Trataremos desse recorte a partir do que Foucault (2002a) nos mostrou sobre o funcionamento da sociedade disciplinar, e de Deleuze (1996), que, na esteira do disciplinamento, nos aponta outros modos de domínio, do tipo exercido pelos efeitos da sociedade de controle.

Trataremos, neste estudo, de descrever os movimentos das duas sociedades (disciplinar e de controle) em seus efeitos no presente, em relação à construção do jogo de verdade, sobre o tema da avaliação escolar, nos programas da disciplina de Avaliação do curso de Pedagogia da universidade escolhida. Este artigo identifica duas arquiteturas curriculares sobre o tema da avaliação escolar e seus efeitos na contemporaneidade: a avaliação classificatória e a avaliação crítica, sendo que tangenciamos essas duas arquiteturas, quando abrimos as brechas da avaliação como poder-saber, atravessados pelas sociedades disciplinar e de controle.

Constatamos, por meio desta pesquisa, que as duas arquiteturas de avaliações escolares, classificatória e crítica, são sintomas de nossas construções e muralhas modernas e que as políticas educacionais, em suas práticas avaliativas, se expandem pelas microfísicas práticas escolares e demais espaços sociais. Vivemos a era da avaliação, seja na escola ou fora dela, invadida por uma perspectiva do disciplinamento e do controle. Diante 
disso, esta escrita busca escavar alguns enunciados das arquiteturas curriculares citados nesses programas, os quais são tomados como possibilidade de apresentar os regimes de enunciabilidade e de visibilidade em se tratando da avaliação escolar na formação de professores de uma universidade.

\section{SEIXOS DA CONSTRUÇÃO DISCIPLINAR E DE CONTROLE}

A sociedade moderna constitui-se em sua relação de imanência com a disciplina a partir de estratégias que realizam um domínio minucioso sobre as operações do corpo de modo microfísico. Foucault (2002a, p. 118) diz que justamente "esses métodos que permitem o controle minucioso do corpo, que realizam a sujeição constante de suas forças e Ihes impõem uma relação de docilidade-utilidade, são o que podemos chamar as 'disciplinas'", as quais funcionam no sentido de apropriar-se das forças do corpo, multiplicá-las, ordená-las, separá-las, diferenciá-las, compará-las e avaliá-las. Dito esse sentido de sujeição do corpo disciplinado, podemos perguntar quais são as ordenações disciplinares no presente, em se tratando dos discursos sobre a avaliação escolar, levando em consideração que somos constituídos como docentes, também pelo funcionamento institucional nas políticas curriculares de formação de professores.

A sociedade disciplinar caracteriza-se e viabiliza-se pela invenção de certos espaços institucionais de confinamento, tais como as prisões, as escolas, os hospitais, os manicômios. As diversas instituições aperfeiçoaram-se e aperfeiçoaram as técnicas de poder. É pelas técnicas de poder que as instituições cumprem sua "missão" social, em que podemos localizar algumas dessas técnicas, como a confissão no discurso religioso, o matrimônio no discurso da família, a descoberta da anatomia no discurso médico e os confinamentos do espaço no discurso dos presídios. Essas são algumas das técnicas de poder que funcionam no microdetalhamentos das operações do corpo, executadas pelas instituições modernas. Para colocar em funcionamento esses tipos de técnicas, a sociedade disciplinar instrumentaliza-se com meios como a vigilância, a sanção normalizadora e o 
exame. A técnica e suas instrumentalizações são parte de um sistema que atua nas forças de esquadrinhamento do tempo, do espaço e dos movimentos dos corpos. Assim, o sistema escolar atualiza-se como anatomia política que contorna e produz existências, tendo como alvo e objeto o exercício de poder em um domínio minucioso das operações sobre o corpo. (FOUCAULT, 2002a).

Para disciplinar, precisa-se determinar quem são os sujeitos, como podem pensar e como vivem, pois, são nessas condições de possibilidade, que se constituem alguns movimentos das ciências humanas nas diferentes instituições, tais como as escolas. E é nesse ponto que a verdade assume papel importantíssimo, pois há toda uma produção de saberes, postos como verdadeiros para disciplinar e governar os indivíduos na escola.

Com a modernidade, institui-se a Pedagogia como ciência, como saber que daria conta da formação humana. A Pedagogia institui-se com um caráter disciplinar, com o objetivo de fixar limites no jogo da identidade e tornar os indivíduos ensináveis, dentro de uma determinada lógica que impõe uma verdade a ser ensinada, de modo a reconhecer e a reconhecerse nela. E é exatamente a partir dessa condição de possibilidade que o sistema escolar institucionaliza o jogo de verdade da avaliação, institucionaliza o exame da verdade sobre os corpos e os saberes.

Esse processo é fortemente atravessado pelos instrumentos disciplinares, do qual falava Foucault (2002a). Pode-se citar a vigilância como uma observação constante que torna o indivíduo conhecível. Do mesmo modo, podemos pensá-la no atravessamento da sanção normalizadora que torna os indivíduos puníveis ou gratificáveis, a partir de determinada norma, já prevendo toda uma maquinaria de correção e autocorreção. Ainda, faz-se necessário marcar o instrumento do exame, com sua importante técnica da confissão e documentação. Foucault (2002a, p. 151) ajuda-nos a pensar tal questão, quando diz que "a disciplina, ao sancionar os atos com exatidão, avalia os indivíduos 'com verdade'; a penalidade que ela põe em execução se integra no ciclo de conhecimentos dos indivíduos". Esse tipo de disciplinamento marca os desvios dos indivíduos, hierarquiza suas 
qualidades, competências e aptidões e também castiga e recompensa, distribuindo promoções que permitem - ou não - a hierarquia e lugares sociais. Dessa forma, "[...] o próprio sistema de classificação vale como recompensa ou punição" (Ibidem, p. 151).

Quando Foucault (2002b) analisou as relações de poder na modernidade, examinou tanto o poder disciplinar, focado no corpo individual, quanto o biopoder, cujo alvo é a população, sendo que este poder funciona sobre os processos biológicos e sociais de massa. Daí podermos considerar a avaliação escolar como algo que opera esse nexo entre disciplinamento do corpo e regulamentação da população em escolas e universidades.

E no processo de análise das relações de forças sobre o disciplinamento dos corpos, encontram-se outras composições no presente, tal como a sociedade de controle, que captura os códigos produzidos nas sociedades descritas anteriormente. Os discursos dessas sociedades articulam-se, não sendo partes separadas do pensamento contemporâneo, uma vez que podem ser problematizados nessas cartografias que nos atravessam.

A sociedade de controle no contemporâneo acopla-se à sociedade disciplinar e funciona sob a força da senha, da digitalidade, da virtualidade, do marketing, do endividamento e da vida em três dimensões (3D): vida vigiada por satélite, senhas e GPS. Opera menos com o confinamento, acionando mais a proliferação identitária, uma vez que necessita cada vez menos dos espaços físicos institucionais de confinamento para controlar os corpos. O que ela necessita é dominar os corpos por outros meios, agora pelas tecnologias do poder voláteis (DELEUZE, 1996).

Assim, vive-se o jogo de dominar o controle e de ser controlado. Os indivíduos tornam-se dados, que são inseridos a todo o momento no sistema, estando sempre à disposição, com isso, operacionalizando uma lógica de visibilidade máxima. Trata-se de um processo que nunca termina, em um panóptico que agora está generalizado, que parte do corpo disciplinado, mas que se expande e se multiplica para constante atualização (DELEUZE, 
1991S6). Ser controlado e controlar são tentáculos de um sintoma de existência contemporânea. Controlar e ser controlado são formas de dominação sofisticadas na atualidade (Ibidem). Trata-se de uma sociedade transparente, na qual a visibilidade é assumida como importante valor. Moraes e Veiga-Neto $(2008$, p. 1) argumentam que vivemos um importante deslocamento no presente do aluno dócil para o aluno flexível:

\begin{abstract}
Atualmente, praticamente todas as formas de processamento da informação, inclusive as telecomunicações, são fornecidas em formato digital, e estão, cada vez mais integradas na mesma rede planetária operada por computadores. Essa tendência para uma computação onipresente e acoplada aos corpos marca a emergência de uma sociedade hiper-conectada em que se deve, constantemente, estar conectado ao fluxo contínuo e global de informações digitalizadas, onde "consumir informação" e "tornar-se informação consumível" geram situações e experiências que são quase sempre tidas como desejáveis ou, até mesmo, necessárias. Essas situações funcionam tanto como elementos de controle e distinção social, quanto como poderosos dispositivos de subjetivação.
\end{abstract}

Nessa perspectiva, o currículo flexibiliza-se cada vez mais, mas, ao mesmo tempo, as avaliações em larga escala, produzem o paradoxo de novas territorializações escolares e acadêmicas, e é aí que podemos pensar a avaliação no jogo de poder e modos de subjetivação. Aqui entendemos e pontuamos a diferença entre a discussão da avaliação individual dos alunos na escola e as discussões sobre as avaliações em larga escala na atualidade, que nos tornam dados inseridos a todo o momento no sistema. Do mesmo modo, marcamos a diferença que se abre entre a avaliação na escola e a avaliação na Universidade, em cursos de graduação, atravessados por outros tipos de classificação e marcadores.

Abre-se, assim, ampla possibilidade de consumir informação sobre a avaliação e rankings entre escolas, redes de ensino, universidades, ao mesmo tempo, convertendo os sujeitos e essas instituições em informação consumível, mediante a combinação de avaliação e estatística. Trata-se, pois, de complexos bancos de dados digitais que trazem a verdade sobre os sujeitos e seus processos de aprendizagem e não aprendizagem, de competências e não competências, de responsabilização e não 
responsabilização, mas ainda a partir de uma perspectiva binária. Podemos pensar com Veiga-Neto (2012) sobre o quanto a ênfase curricular entendendo o currículo como o principal artefato escolar que produz modos de subjetivação na modernidade - vem sendo pautada cada vez mais pela avaliação como um efeito da dominação da sociedade de controle que produz modos de existência nessa perspectiva. Conforme o autor,

[...] O ranqueamento é função de uma associação entre ordenamento e hierarquização; um ranking é uma classificação cuja ordem obedece a determinados critérios que expressam, por si só, determinado(s) juízo(s) de valor. Um tanto tautologicamente, os juízos de valor entram nas duas pontas do processo: antes, eles enformam os critérios para, depois de tudo ordenado, se revelarem para nos informar o valor de cada um: quem está nos extremos (mais altos e mais baixos), quem ocupa as faixas intermediárias, como se distribuem os diferentes elementos do conjunto em questão. Os juízos de valor enformam (antes) e nos informam (depois) (VEIGA-NETO, 2012, p. 10).

As instituições escolares atravessam o disciplinamento dos corpos e o controle dos públicos, por meio de inúmeras técnicas de poder, dentre elas, talvez uma das mais imperativas seja a avaliação. Os processos avaliativos, como os conhecemos hoje, foram inventados a partir de uma lógica disciplinar e, na atualidade, são também capturados pela sociedade de controle. As tecnologias de avaliação da aprendizagem, cada vez menos necessitam dominar os corpos em espaços de confinamento, mas sem abrir mão de sua dominação.

Os corpos, sob avaliação, estão sendo recodificados no mundo do controle, e é para lá que uma parte da construção da muralha está rumando. Escolas, universidades e a formação de professores afirmam-se sobre uma crise do disciplinamento. Talvez seja uma das expressões coletivas de que são as técnicas disciplinares e suas operacionalizações, não funcionam mais com tanta eficácia. Isso não quer dizer que tenham funcionado, em algum tempo, de modo total. As resistências/brechas nunca deixam de operar, mas houve um tempo em que as instituições de confinamento, eram quase centrais para o funcionamento dos indivíduos e da população. Portanto, parte-se de um corpo disciplinado, exercendo-se 
seu domínio além das muralhas no presente. Os aparatos de domínio, então, são agora também de controle, atualizando-se em uma existência que se afirma neste jargão encontrado em estabelecimentos públicos e em muitas instituições de ensino, inscrito, em diversos espaços da atual sociedade: Sorria, você está sendo controlado!

Partindo desse posicionamento, destacaremos alguns enunciados presentes na formação de professores sobre o tema avaliação escolar, retirados dos programas da disciplina de Avaliação de um curso de Pedagogia.

\section{CONSTRUÇÕES DOS DISCURSOS DA AVALIAÇÃO ESCOLAR NO CURRÍCULO DE FORMAÇÃO DE PROFESSORES}

A escola é uma das instituições disciplinares que se afirmam na fronteira entre um poder pastoral de uma moral cristã, que busca a salvação do rebanho pela obediência e confissão da verdade, e uma lógica governamental, focada no controle da população, por meio de mecanismos de segurança e de um governo político dos homens. Herda, portanto, a emergência de tirar a humanidade do misticismo, do senso comum e da "escuridão medieval", passando a ser parte da missão moderna de civilizar e implantando os valores de mercado livre, de consumo e da lógica científica, higienizadora e conscientizante.

Com isso, a instituição escolar também se compõe no pacto de dar seguimento à missão civilizatória. Para tanto, organiza-se com aparatos didáticos que agem sobre o corpo, o tempo e o espaço. Outro ponto relevante que legitima a força da missão das instituições escolares é o fato de que, as questões didáticas passam a ser reconhecidas como parte da ciência, territorializando-se em Pedagogia. Esta, por sua vez, teria por função estudar os sujeitos e seu desenvolvimento, classificar suas capacidades intelectuais e morais. Ou seja, no projeto moderno disciplinar e, mais contemporaneamente, de controle, a escola constitui-se com a função de classificar e diferenciar as etapas do humano e passa a demarcar também o poder da aprendizagem e o saber de como avaliar a aprendizagem. 
A Pedagogia, como área do conhecimento que especificamente produz uma série de clássicos conceitos sobre a atuação no ensino ${ }^{3}$, narra vários modos de ocupar o território da didática, apoderando-se dos conceitos de: conteúdo de ensino, objetivos de ensino, métodos de ensino, estratégias de ensino, planos de ensino, técnicas de ensino, aprendizagem e avaliação. Dessa maneira, constituiu-se na esteira do funcionamento do disciplinamento e do controle, passando a definir a normalidade e a anormalidade das pessoas na escola e na universidade, com um modo de governo: "através dessas diferentes práticas - psicológicas, médicas, penitenciárias, educativas - formou-se certa ideia, um modelo de humanidade; e esta ideia do homem tornou-se atualmente normativa, evidente, e é tomada como universal". (FOUCAULT, 2004, p. 300). Isso também significa que o currículo vem se deslocando do ensino para a aprendizagem contemporaneamente, fortemente associado à necessidade de avaliação. O currículo, pois, assume a avaliação como um conceito universal, que determina a veracidade, medida do exercício intelectual e da moral, atravessando saberes e métodos pedagógicos validados por dados, constatações, pareceres, descrições, menções, notas e medidas expressas como avaliação.

Então, nesse modo de governo curricular, constitui-se uma relação com a avaliação no decorrer das várias posições do ensino e da aprendizagem. Dizemos que, em torno do currículo, se produz uma variedade de clássicos conceitos sobre avaliação, engendrados na tradição das sociedades modernas, tendo sido "historicamente criada pela própria escola, na escola e para escola" (CHEVAL, 1990, p. 181). Já na sociedade de

\footnotetext{
${ }^{3}$ Se ocuparmo-nos do artigo História das disciplinas escolares: reflexões sobre um campo de pesquisa, do historiador francês Cherval (1990), encontraremos o argumento de que os ensinos escolares provocam a aculturação conveniente e de que o ato de ensinar, no século XX, se relacionava com a noção de instruir, educar, lecionar, mas o uso do verbo ensinar restringiu-se, principalmente, ao exato termo disciplina. Já a tese de doutorado de Carlos E. Noguera-Ramírez, Pedagogia e governamentalidade: ou Da Modernidade como uma sociedade educativa, mostra os deslocamentos do conceito de ensino e, mais contemporaneamente, aponta a emergência de uma sociedade da aprendizagem espalhada em diversos espaços sociais.
} 
controle, extrapola-se sua criação nas dobras de outros espaços que atravessam essa maquinaria.

A avaliação escolar é, então, um dos sintomas curriculares herdados na produção da sociedade disciplinar e expandido na sociedade de controle. As suas tecnologias de poder curricular, engendradas pela Pedagogia, são trazidas nas vastas bibliografias e investigações sobre essa temática. Encontramos, nessa investigação, uma composição entre atuaação curricular e a avaliação escolar. É com essa construção, sem a negarmos, que compomos a seguinte inquietação: como a avaliação escolar se operacionaliza nas sociedades disciplinar e de controle no presente em um curso de Pedagogia? Para movimentar essa pergunta, cabe demarcar que o currículo é tomado como uma força que produz a avaliação como uma tecnologia de poder. Diante disso, passamos a delimitar duas arquiteturas curriculares: a avaliação classificação e a avaliação crítica, trazendo a possibilidade de as tomarmos como estratégias de poder-saber, como trataremos a seguir.

\section{Arquitetura curricular: avaliação classificatória}

Nos programas da disciplina de Avaliação do curso de Pedagogia examinados, é encontrado facilmente o discurso da avaliação classificatória. Esse tipo de avaliação carrega os conceitos e bibliografias de cunho curricular, a partir da formação de professores, com ênfase no tecnicismo, sendo alvo de questionamentos da literatura denominada crítica (SILVA, 1999).

Encontramos vastas publicações bibliográficas nos programas, que passam a destituir as produções pedagógicas de ensino e aprendizagem propostas pelo pensamento classificatório. A principal crítica que o pensamento crítico faz à avaliação classificatória é que ela atua em uma sociedade que age como uma máquina, isto é, que vive com engrenagens articuladas na produção de indivíduos para o mercado de trabalho. Os discursos escolares mergulhados nesta maquinação construiriam um aparato 
pedagógico que opera com o ensino como reprodução, medição, adaptação e classificação (MATOS, 2009).

Uma das principais características desse tipo de avaliação é que ela necessita ser diretiva e objetivar metas, havendo uma exigência de posição autoritária e neutra por parte do bom educador e, por outro lado, esperando-se uma posição passiva e adaptativa do bom estudante. A aprendizagem é, nessa lógica, vista como uma reprodução, uma transmissão de ideias que alimentam essa maquinaria, sendo que as aprendizagens serviriam para adaptar as pessoas ao mundo do trabalho e da moral, bem como, para a produção de consumo. A partir dessa perspectiva, busca-se eficiência, padronização e medição quantitativa de resultados, de modo linear, e hierarquizado, a fim de operar com significados fixados, uma vez que as matérias escolares são tidas como objeto de lógica (MATOS, 2009).

Sendo assim, a avaliação denominada classificatória é tratada, na maioria das vezes, pelos programas da disciplina de Avaliação na formação de professores desse curso de Pedagogia, como força política para medir e classificar os resultados, dando conta do funcionamento da sociedade disciplinar, que necessita de indivíduos bem treinados para dar continuidade ao progresso e à civilidade. Os conhecimentos dos alunos passam a ser medidos por testes padronizados, e os professores passam a ser treinados como técnicos. A escola é entendida como uma máquina que fabrica indivíduos dóceis e úteis para a sociedade industrial capitalista. Podemos, então, pensar essa perspectiva como imanente à modernidade, que parte de uma lógica racionalista e cientificista, segundo a qual a ênfase da aprendizagem está na memorização e na medição da individualidade que busca a competitividade.

As tecnologias avaliativas desencadeadas pelo procedimento tecnicista destacam-se pela forte crença no controle dos resultados da avaliação e na captura da inteligência dos alunos, sendo os resultados constituidores de uma visão universal e generalizada sobre os fatos aprendidos e não aprendidos. Essa é uma das crenças presentes na 
avaliação de discurso classificatório, que tem que dar conta do projeto moderno de educar e trazer todos para a escola. Medir os resultados avaliativos é a força da seletividade e da produtividade de resultados. A medida é dada dentro do escore de valor moral, que usa instrumentos como notas e escore de habilidades e competências para determinar o bem e o mal no sistema escolar.

O currículo, nesse sistema de avaliação, é seletivo e, em nome da seleção, faz o procedimento excludente. Não há espaço para a diferença e para a singularidade. O sistema aponta os mais bem adaptados ao controle social vigente, comparando-os e classificando-os por meio de escores, graus e menções de maior alcance numérico. Os números funcionam como forças exatas que respaldam a ciência da avaliação normativa e que servem como uma tecnologia comprobatória da escola sobre a capacidade do aluno e do trabalho do professor e dirigentes escolares.

Os valores da avaliação classificatória estão ligados ao julgamento moral dentro do jogo do bem e do mal. Para demarcar a categoria binária, faz-se necessário realizar um escore de critérios que correspondam ao bem, sendo impregnados de meios numéricos de ordenação classificatória hierárquica de maior valor para o menor valor. A apreciação do bom aluno e da aprendizagem satisfatória têm correspondência direta com o valor do bem. Os valores científicos verdadeiros, atrelados à moral cristã e aos valores de consumo burguês, produzem o aparato de quem domina e vive o bem e excluem os que não dominam esse aparato do funcionamento institucional.

Portanto, os corpos que não dominam e não são dominados por essas forças classificatórias estão na categoria do mal e dos reprovados na avaliação escolar, com toda valoração e efeitos de verdade produzidos nesse processo. Poderíamos, em outra perspectiva curricular de formação de professores, perguntar-nos com Nietzsche (1998, p. 45): "sob que condições o homem construiu os julgamentos de valor? ". 


\section{Arquitetura curricular: avaliação crítica}

Ainda diante dos dados extraídos dos programas da disciplina de Avaliação do curso de Pedagogia, explicitam-se outros conceitos e bibliografias que expressam outro currículo na formação de professores sobre o tema avaliação. Apresenta-se, em todos os programas, o currículo crítico (SILVA, 1999), em oposição ao pensamento tecnicista em educação. Esse currículo movimenta inúmeras composições avaliativas que ressaltam outros valores sociais, e não somente os que estão a serviço do mercado/consumo e da competitividade.

Os pensadores do ideário progressista e críticos educativos revisitam os valores econômicos e sociais, propondo uma economia solidária, justa, participativa e cooperativa. Para isso, faz-se necessária outra posição das pessoas envolvidas no ato educativo, tal como uma atuação mais consciente por parte delas, o que se faz por meio de denúncias, das formas sociais dominantes e de forças majoritárias. Sobre esse vetor curricular crítico, encontramos nos manuais da História da Pedagogia no Brasil as denominações das pedagogias: libertária, libertadora, progressista, pedagogia social dos conteúdos, emancipatória e multiculturalismo, entre outras (SILVA, 1999).

Mesmo sabendo que existem diferenciações conceituais entre essas denominações, as aproximamos pelo posicionamento dialético que todas carregam e pela busca por ampla participação coletiva, pelo direito ao exercício da cidadania, pelo desmascaramento das ideologias dominantes e pela tomada de consciência pelas pessoas. São teorias operando em busca de práticas educativas que levem à construção de cidadãos que conheçam seus direitos e deveres sociais e a eles tenham acesso irrestrito.

A escola, para este território pedagógico dialético, é vivida como um meio de transformação e de luta social frente às injustiças políticas, pela explicitação de um currículo que estaria oculto, produzindo desigualdades, no qual os educadores seriam como que agentes do processo educativo e avaliativo. Todavia, o pensamento crítico-dialético faz essa análise sem sair da ordem da transcendência social e individual, sem problematizar a matriz 
pautada na vontade de verdade em que reside. Sua ação a partir de uma lógica identitária afirma-se na racionalidade social em busca da salvação, de uma verdade da moral conscientizadora (SILVA, 1999; GARCIA, 2002a, 2002b).

Mesmo sabendo que há outras produções discursivas sobre a avaliação, na perspectiva crítico-dialética, trazemos tipos discursivos que mais se apresentaram nos enunciados bibliográficos dos programas da disciplina de Avaliação, a saber: a avaliação emancipatória (FREIRE, 1992; VASCONCELOS, 1993) e a avaliação mediadora ou significativa (HOFFMAN, 1991). Traçaremos, a seguir, algumas de suas linhas discursivas.

A avaliação emancipatória (FREIRE, 1992) leva em consideração o processo de descrição e análise das especificidades que compõem determinada realidade socioantropológica. Esse modo de investigação busca a transformação sociopolítica dessa realidade, em busca da equanimidade social. Para tanto, faz-se emergente a avaliação que emancipe, ou melhor, uma avaliação que parta da libertação dos determinismos políticos educacionais e culturais vigentes.

Nesse estudo antropológico da realidade, os sujeitos envolvidos no sistema escolar atuam diretamente na solução das problemáticas sociais, procurando gerar suas próprias histórias de modo participativo e autônomo. Assim, a avaliação torna-se emancipação quando se produzem alternativas para transformar a realidade desse sistema educacional. A autonomia como participação faz-se pelas tecnologias de poder instauradas nas audiências coletivas em sala de aula para potencializar as decisões, no sentido participante e conscientizador - um tipo de posição de engajamento político comunitário dos envolvidos no processo educativo que desenvolve o processo emancipatório (FREIRE, 1999).

A perspectiva emancipatória toma o instrumento de avaliação como ato educativo em uma consciência crítica, nas quais os sujeitos envolvidos partilhariam as decisões avaliativas, responsabilizando-se coletivamente pelas ações de estudo e de ensino. Sendo assim, as decisões sobre a avaliação requerem um fórum de consenso. Também se opera nessa 
perspectiva com outros procedimentos avaliativos escolares como atitude emancipadora, tais como as observações e os registros de falas dos participantes de uma determinada instituição (FREIRE, 1979).

Avaliar, portanto, é selecionar coletivamente quais são os saberes e poderes que devem ser refletidos para um processo conscientizador. A própria escolha do saber e os contornos de poder que nele estão são o ato avaliativo emancipatório. Trata-se de potencializar os alunos e comissões diretivas para assumirem a autoavaliação como uma libertação provisória do sistema de opressão educativo burguês, aristocrático, técnico e bancário. A aprendizagem e o conhecimento ficam à disposição da efetiva mudança de ação conscientizadora, em que o tradicional conteúdo escolar é transformado em saberes que potencializariam os agentes educativos na ação crítica. Dessa forma, a avaliação deve ser construída em todos os momentos pedagógicos, e não somente ao final como resultado, colocando-se como processual e contínua (FREIRE, 1979).

Nessa perspectiva, os alunos participam da elaboração dos critérios avaliativos quanto a si mesmos e também passam a avaliar os professores e a própria escola, sendo aqui a responsabilidade e a flexibilidade fortemente valoradas. Como diz Freire (1999, p. 71), "o ideal é que, cedo ou tarde, se invente uma forma pela qual os educandos possam participar da avaliação. É que o trabalho do professor é o trabalho do professor com os alunos e não do professor consigo mesmo". Continuando, acrescenta: "[...] saber que devo respeito à autonomia, dignidade e à identidade do educando" (Ibidem, p. 72).

Enunciava-se também, nos conceitos e bibliografias dos programas da disciplina de Avaliação, o traço do discurso de avaliação mediadora ou significativa (HOFFMANN, 1991). Essa avaliação tem duas direções convergentes, uma na direção da realidade cognitiva e outra na da realidade socioeconômica. Ambas operam com conceitos mediados pelo diálogo comunicativo.

A realidade cognitiva é parte da teorização da epistemologia construtivista, que esse sistema de avaliação explicita em método 
investigativo, a partir do que segue: observa as etapas do desenvolvimento cognitivo, oportuniza desafios cognitivos, registra as manifestações de diálogo individual, dentro da ação coletiva e resgata o cotidiano mediante os conhecimentos denominados de prévios. Walkerdine (1999), em seus estudos, aponta os efeitos dessa perspectiva, que se coloca como uma alternativa a uma lógica reacionária e tecnicista, mas que parte de toda uma maquinaria de observação, monitoramento e registro do desenvolvido tido como normal de crianças e adolescentes, transformando-os em objetos de um olhar científico e pedagógico, por meio de mecanismos que têm como intenção a sua libertação.

O valor desse tipo de avaliação está no processo vivido cognitivamente e socialmente, nas significações denominadas pelas situações vividas. Os instrumentos de avaliação mediadora têm como função acompanhar o processo cognitivo evolutivo, com registro em diário, relatório, portfólio comentado, pareceres descritivos e autoavaliações individualizadoras. Quanto a esta última, Larrosa (2000) chama atenção para a questão de como os alunos aprendem a classificar as condutas em tolerantes ou intolerantes, valorizando esse primeiro valor e avaliando-se em relação a isso. Como exemplo, o autor considera a autoavaliação como um momento que traz consigo uma conduta de exame, de autolembrança e de auto-observação, com o objetivo de desempenhar aquilo que se espera dos alunos, e isso está ligado à posição que o sujeito ocupa ou deve ocupar no discurso pedagógico.

Esses instrumentos são tecnologias de poder que comprovam o diagnóstico das aprendizagens dos alunos, por meio das quais se mantêm ou se reelaboram o planejamento e as atividades de sala de aula. A avaliação mediadora faz a intervenção entre o senso comum, os conhecimentos científicos, os conhecimentos escolares e o desenvolvimento sociocognitivo dos discentes. As intervenções são procedimentos didáticos produzidos pelas pedagogias construtivistas e sociointeracionistas, as quais buscam por uma aprendizagem denominada como significativa e também são fortemente operadas via autoavaliação. Para Garcia (2002a, p. 64), 
As práticas auto-reflexivas envolvem toda uma série de tecnologias intelectuais, orais e escritas, que vão desde os relatos orais e os "diários" de classe do professor, às fichas de observação e autoavaliação, aos relatórios de observações da prática e de estágios, etc. Formas de mostrar-se ao outro, de dar-se a ver a olhares e ouvidos atentos, de objetivar-se a si próprio, possibilitando a correção e a autocorreção.

Trata-se, pois, de certo regime do eu e de certo modo de governo, perpassados por conscientização, participação e bem agir nesses dois tipos discursivos descritos, a partir de uma perspectiva crítica. São modos que Garcia (2002a, 2002b) diz assumirem uma perspectiva crítico-pastoralhumanista, operada agora no governo político dos homens, fortemente produzidas por meio de tecnologias de autorreflexão, autoconhecimento e autodeterminação, o que nos leva a pensar nos processos avaliativos. Ou seja: o processo de avaliação e de correção viria de normas inscritas na própria identidade de alunos e de professores. Isso nos faz pensar, no quanto, práticas pedagógicas neoliberais e também práticas progressistas de resistência à lógica neoliberal, na contemporaneidade, utilizam-se dos conceitos de autonomia, flexibilidade, colaboração, mediação, liberdade de escolha e autoavaliação para encaminharem seus processos, mesmo que em perspectivas teóricas contrárias.

Esses dois procedimentos avaliativos, emancipatório e mediador, têm foco na interação e na participação, ganhando força de instrumento politizador e investindo na competência crítica e autocrítica dos educandos e educadores. Os espaços pedagógicos são vividos no campo dialético e no campo de visões contraditórias, por isso, fazem do diálogo um dos fortes instrumentos de tecnologia de poder. Os procedimentos escolares, diante desse pensamento, articulam-se com planejamento participativo de representatividade coletiva, $O$ que requer um acompanhamento $e$ envolvimento sistematizado, pois a avaliação é o acolhimento das possibilidades e das limitações de determinada realidade cognitiva e social. Consideramos que esse procedimento avaliativo é parte de um ajuizamento das qualidades individuais, potencializando-as em uma ação coletiva. 
As avaliações emancipatória e mediadora, portanto, fazem-se por dentro da ideia de que existe um currículo oculto no processo social e de que este deve ser des-ocultado. Os processos de conscientização se dariam ao descobrirmos o lado oculto da realidade. Sendo assim, teriam o poder de reverter as questões sociais por meio da educação. "Quem escondeu o currículo oculto?", pergunta o autor Silva (1999, p. 77). Quem escondeu as atitudes, os comportamentos, os valores e as orientações escolares? Há ocultação? Há algo para ser descoberto?

Podemos retomar a função disciplinar da instituição escolar e o próprio funcionamento da sociedade disciplinar e de controle atualizados no presente em se tratando da avaliação e suas forças no domínio dos corpos e das populações. Ensinamos o disciplinamento e controle mediante rituais de organização do tempo, espaços e movimentos, regulamentos, normas, rankings e processos avaliativos mais gerais, em que valoramos os veredictos da avaliação.

A produção desses dois tipos discursivos de avaliação na construção da pedagogia crítica atua igualmente com a moral do bem e do mal. $O$ discurso do bem é acoplado na identidade do avaliador justo e politicamente engajado, que atua pela transformação na conscientização social por meio da denúncia do movimento opressor e da reprodução social na escola. Esse funcionamento carrega a lógica identitária originária e a vontade de verdade, que é a moral que funda as práticas nas quais vivemos.

\section{BRECHAS NA CONSTRUÇÃO CURRICULAR: avaliação como estratégia de poder-saber}

A partir dos movimentos da sociedade disciplinar e de controle, há uma produção curricular, no que diz respeito à avaliação em suas relações de poder e saber, uma vez que essas movimentam técnicas de dominação que estão em mudança. Ouvimos de Kafka (2002b, p 164), especificamente no conto produzido entre 1914-1924, As investigações de um cão, a seguinte inquietação: "[...] por que censura nos outros o seu silêncio e você mesmo se 
cala? A resposta é fácil: Porque sou um cão". Captura kafkiana do funcionamento da sociedade de controle. Esta não necessita mais dos aparatos de confinamento e clausuras para produzir civilidade. Talvez, parta do corpo disciplinado para funcionar por outras tecnologias de poder. Por isso, encontramos as novas narrativas em educação, que se estendem em uma espécie de controle remoto, pois se percebe que a muralha curricular não domina mais os corpos, não os faz parar, pois o controle das condutas se expande em outras perspectivas no presente.

A avaliação escolar contorna os seixos das relações de poder e saber. Localizamos conceitualmente o poder-saber determinado por forças dos programas da disciplina de Avaliação de um curso de Pedagogia. Forças curriculares que, nesses programas, diminuem a vida quando operacionalizam a avaliação como exame (FOUCAULT, 2002a); vigiam-se e sancionam-se os indivíduos por meio de gratificações e punições, fazendo-os confessar, dividindo-os e hierarquizando-os em padrões de normalidade, inteligência e sucesso a partir do discurso contemporâneo. Exige-se de cada aluno que escreva a fim de demonstrar a verdade sobre si mesmo, e isso é medido numericamente ou conceitualmente. Aos indivíduos, são atribuídas notas, e suas qualidades são quantificadas em uma ciência moderna que esquadrinha e registra a vida de forma escrita, documental, tornando cada aluno um caso para si mesmo e para os demais. O exame, segundo Foucault (2002a), opera fortemente o nexo entre saber e poder, uma vez que se instituem determinados saberes para a construção de categorias da avaliação escolar, mediante um saber necessário para a construção da formação de professor. Trata-se de um escrutínio que coloca em funcionamento exames de consciência, processos de confissão, e o aluno é tornado um caso, virando, em seguida, um dado documentado de parecer, boletim ou estatísticas.

O poder dessa avaliação não está em dizer o que foi ou não aprendido, mas em seu efeito disciplinador, vinculando as pessoas a identidades de normalidade e anormalidade, produzidas a partir de uma 
média, tendo a escola atestados para provar, por diferentes instrumentos, 40 verdadeiro aprendizado do aluno cognitivo. Trata-se da objetivação e subjetivação do indivíduo nessas tecnologias avaliativas, já que, ao mesmo tempo em que o aluno se torna objeto de conhecimento em relação à aprendizagem, desenvolvimento, progresso, sucesso e responsabilidade, ele assume determinados modos de existência a partir disso. Essas são técnicas de poder atreladas a forças do juízo moral em sofisticadas tecnologias de subjetivação.

Dessa forma, podemos entender a avaliação como uma tecnologia de poder-saber e, mais ainda, como uma tecnologia de subjetivação, isto é, como um espaço no qual o indivíduo aprende determinadas formas de se relacionar consigo mesmo, com os demais e com o mundo. Foucault (2002a) enfatiza o nexo entre relações de poder e a constituição de campos de saber. Para o autor, a verdade não existe fora de relações de força. A partir disso, podemos pensar que o regime de verdade de nossa sociedade, em se tratando da avaliação escolar, está assentado no discurso científico pedagógico, invadido por ares neoliberais da cultura do empresário de si, do sucesso e do aprender a aprender na contemporaneidade.

Referimo-nos aqui a técnicas de poder e saber que colocam em funcionamento regras de convivência do bem social, que são regras de condutas banhadas nos valores cristãos e consumistas, por vezes transcritas no conceito de cidadão. São valores pautados pela crença em uma verdade originária, que divide o mundo em verdadeiro e falso, moral e imoral, entre outros, avaliados por comunidades científicas que dominam o bem.

Nietzsche (2008, p.31), em seus escritos, diz: "os juízos de valor morais são condenações. São promoções que condenam o bem e o mal". 0 sentido de viver é atrelado à valoração do bem e do mal, fazendo com que

\footnotetext{
${ }^{4}$ No presente, vivemos outros sintomas diagnosticados a partir de uma série de instrumentos avaliativos, tais como: notas, menções, graus, pareceres descritivos e dados do modelo Rasch (Provinha Brasil), do modelo de três parâmetros (Prova Brasil, ENEM), psicometrias, descritores, parâmetros de proficiências e matrizes referências, entre tantos outros. A avaliação expande-se de modo geométrico. Vivemos a era das avaliações em larga escala e dos rankings entre escolas e redes de ensino.
} 
essas categorias, ao serem colocadas em xeque, produzam como que um não sentido de viver, para os moralistas! Nietzsche (1998) operou com uma genealogia da moral, afirmando que o importante é problematizarmos o valor de nossas valorações. Ao desnaturalizarmos as condições de possibilidade das valorações que as sociedades disciplinar e de controle valoram na avaliação escolar, problematizamos a valoração do bem e do mal; do bom e do ruim; do normal e anormal; da média e do desvio. Trata-se de problematizar essa moral de rebanho que opera por generalizações e essências, a partir da lógica de modelos e cópias e de uma verdade original. Segundo Nietzsche (1998), a moral prescritiva é totalizadora, metafísica, opera com forças reativas e saberes codificados, julga as pessoas a partir de valores superiores.

As tecnologias de poder, produzidas pela avaliação escolar, constituída nos redutos científicos comprovam e divulgam que o bem comum de uma sociedade de cultura civilizada, de cunho participativo comunicador, é a sociedade da comunicação. Portanto, o domínio dos corpos em controle dá-se por meio da opinião e da participação comunicativa, bem como pelo vertiginoso fluxo de informação, como que por uma comprovação identitária. Nunca se avaliou tanto, tantas vezes ao ano, ao mês, na semana, na escola. Veiga-Neto ajuda-nos a pensar tal questão (2012, p. 12):

O que é novo é a exacerbação da avaliação, em termos da sua intensidade e principalmente da sua onipresença e atravessamento em todas as esferas da nossa vida. É novo, também e não menos importante, o caráter radicalmente econômico que a avaliação assume nas sociedades neoliberais. $E$, em termos educacionais, nunca será demais repetir: o que é novo é fazer da avaliação uma tecnologia de inspiração econômica que não apenas classifica, segrega, posiciona, hierarquiza, mas que também ensina, promove e naturaliza a classificação, a segregação, o posicionamento e a hierarquização sociais. Basta compreender tais novidades para compreendermos porque a avaliação transformou-se num farol para o currículo.

No presente, esse controle via avaliação espalha-se, e o panóptico generaliza-se. As provas nacionais com pretensões de medições totais 
colocam em funcionamento uma lógica de controle à distância. A partir dessas avaliações, os dados são inseridos no sistema, e deles são feitas estatísticas, que falam do nível de educação de cada região, do nível de alfabetização de cada lugar e assim por diante. Trata-se de uma série de cálculos e reflexões que marcam os indivíduos como população a ser gerenciada, mapeando o que é normal de ser esperado e produzindo uma série de estratégias, tal como conectar o financiamento de políticas a tais medições. Aqui pontuamos novamente que essas duas dimensões da avaliação (individual do aluno e as avaliações em larga escala) se entrecruzam e se produzem mutuamente.

É possível dizer que o juízo moral do bem e do mal na avaliação, também é parte de uma lógica de controle da população, por meio do domínio de certa condução das condutas. Nossas avaliações escolares, quando ajuízam o bem e o mal, produzem interioridades, fixam o sujeito a certas verdades, a certa moral; amarram o indivíduo a uma identidade, tal como a identidade do analfabeto, do aluno com dificuldades de aprendizagem, do aluno com sucesso, entre tantas outras postas para serem gerenciadas mediante tecnologias de poder-saber na escola. Será, pois, possível avaliar além do juízo do bem e do mal?

Esse tipo de investigação das malhas do poder-saber nas avaliações coloca-se no sentido de buscar entender melhor como estão funcionando as tecnologias de poder em seus efeitos de verdade e de subjetivação, buscando-se, talvez, enfrentamentos mais afirmativos e menos romanescos da sociedade e da escola. Todavia, na contemporaneidade, não se trata mais de disciplinamento, ou melhor, não se trata apenas de disciplinamento, mas também de controle. Avaliar não se faz somente objetivando metas, mas dominando as comunicações, os dados, os saberes, isto é, controlando o controle.

A escola, como uma das instituições civilizatórias, passou a criar e aperfeiçoar as suas tecnologias de poder, sendo fortemente atravessada no presente pelo léxico empresarial e por certo um tipo de aceleramento na produção. Assim, o poder é ação de afetar e ser afetado por corpos em 
(im)posições de sentidos. O poder é entendido não como uma coisa que se possui, mas como uma relação que se exerce - relação de forças com outras forças, como relações capilares, espalhadas por toda a teia social, intimamente relacionadas com a produção de saberes. Podemos pensar no poder soberano, nas disciplinas, no biopoder e no controle como diferentes modos de o poder exercer-se. Olhar para a produção das tecnologias de poder constituídas em determinadas épocas em nossas sociedades é fazer delas sintomas que expressam a produção de certos modos de existir.

As tecnologias avaliativas buscam conduzir as condutas dos indivíduos, por meio de uma série de procedimentos, tais como: as classificações por séries e por idade, o caderno de ocorrências, as regras de convivência, as hierarquias profissionais (diretor, supervisor, professor, aluno, comunidade, entre outros), os livros didáticos, assim como a organização do ensino mediante a disciplina e a prática de exames individuais e coletivos. Avaliação em processo, classificatória, emancipatória, formativa, externa, interna. Estende-se a técnica de dominar o espaço-tempo com rotinas, provas, autoavaliações, números, posições discursivas. Essas são algumas das técnicas de poder produzidas e atreladas à maquinação capitalística que possibilita disciplinar e controlar indivíduos, produzindo determinados modos de subjetivação, consumidores, cidadãos, trabalhadores, empreendedores de si, etc.

A avaliação, enquanto parte dos clássicos conceitos da didática, passa a ser produtora de modos de existência, pois suas atuações carregam as concepções de sociedade e de escola que fomos, somos e já estamos deixando de ser. A subjetivação é aqui entendida não como algo interno ao sujeito ou algo que é trazido de fora e interiorizado pelo sujeito, mas como relação de forças entre diferentes movimentos e combinações; como uma forma, e não como uma essência. Os modos de ser que aprendemos a assumir como nossos, como interioridade e identidade, são produções que não existem fora de processos sociais, de relações de poder e saber, que nos atravessam e que atravessamos e às quais nos submetemos ou buscamos resistir. 
Assim, a avaliação, com seus critérios de valores morais e cognitivos, produz modos de existência. Daí a importância de estarmos atentos aos ajuizamentos de valores que orientam nossos processos avaliativos e aos quais nos unimos. Cabe considerar, se estes conduzem para uma produção afirmativa de subjetividade, para microfísicas resistências à lógica capitalística contemporânea ou se a confirmam, por exemplo. Não se trata de duas totalidades binárias, de estar de um lado ou de outro, mas de diferentes brechas nas quais vamos experimentando outras possibilidades. Talvez essa postura não traga certezas e cálculos prontos, pois opta por não operar com o romantismo pedagógico, apostando na criação de outras possibilidades de pensamento.

\section{CONSIDERAÇÕES FINAIS}

Nossa problematização se dá, pois, a partir de uma inspiração kafkiana, em meio a uma construção de muralha de seixos, sobre o tema da avaliação no currículo da formação de professores em uma universidade no sul do Brasil.

Apresentamos, nesta escrita, duas arquiteturas de investigação sobre a avaliação escolar, entendendo-a como prática discursiva atrelada às sociedades disciplinar e de controle. A avaliação é extremamente valorizada no campo do currículo de formação de professores do curso de Pedagogia, constituindo-se em um valor com força moral e científica, legitimada para determinar modos de ser na contemporaneidade, assumindo um funcionamento no domínio dos corpos.

Compreendemos que esse tipo de investigação toma os enunciados encontrados nos programas da disciplina de Avaliação de um curso de Pedagogia, como sintomas de nosso processo educativo, e não como vereditos sobre ele. Demarcamos uma produção curricular e algumas de suas tecnologias de poder, produzindo condições de possibilidade de problematizar a naturalização da avaliação escolar e mostrando algumas das vontades de verdades enunciadas a partir dela. Esse tipo de problematização poderia funcionar com forças para deslocar a avaliação 
para uma linha de resistência, como se fosse uma brecha na muralha de Kafka (2002a).

Problematizar os regimes de verdade vigentes em seus efeitos específicos de poder, saber e subjetivação na avaliação escolar, em se tratando da formação de professores no curso de Pedagogia, implicou tomar a avaliação como uma tecnologia de poder, possibilitando-nos indicar o modo de valoração dos valores que operacionalizamos na arquitetura das construções. Isso não significa operar sem nenhum valor ou abrir mão deles, mas pensar e problematizar como estamos atuando em relação a isso. Ao problematizarmos essa construção específica que é a avaliação escolar, poderemos pensar em outras relações que não recorram, tão rapidamente, aos discursos verdadeiros, às didáticas estruturalistas, às totalidades e identidades já disponíveis, nem às medições de toda ordem. Trata-se de um singelo habitar provisoriamente nas brechas da muralha desta construção que, talvez, nos possibilite abrirmo-nos para o inédito produzido no encontro dos corpos.

\section{REFERÊNCIAS}

CHERVAL, A. História das disciplinas escolares: reflexões sobre um campo de pesquisa. Teoria \& Educação. A nova direita e a educação. $O$ mito da alfabetização. Os saberes escolares. Porto Alegre: Editora Pannonica, V. 2, p. 177-229, 1990.

DELEUZE, G. Post-scriptum sobre as sociedades de controle. In: DELEUZE, G. Conversações. 1972-1990. Tradução de Peter Pál Pelbart. Rio de Janeiro: 34, 1996, p. 219-226.

FOUCAULT, M. Vigiar e punir: nascimento da prisão. Tradução de Raquel Ramalhete. $25^{\circ}$ ed. Petrópolis: Vozes, 2002 a.

FOUCAULT, M. Em defesa da sociedade: curso no Collège de France (19751976). Trad. Maria Ermantina Galvão. São Paulo: Martins Fontes, 2002b.

FOUCAULT, M. Verdade, poder e si mesmo. In: FOUCAULT, M. Ética, sexualidade, política. Ditos e escritos. V. Tradução de Elisa Monteiro, Inês Autran Dourado Barbosa. Rio de Janeiro: Forense Universitária, 2004, p. 294300.

FOUCAULT, M. Segurança, território e população: curso no Collège de France (1977- 1978). Tradução de Eduardo Brandão. São Paulo: Martins Fontes, 2008. 
FREIRE, P. Educação e mudança. São Paulo: Editora Paz e Terra, 1979.

FREIRE, P. Pedagogia da esperança: um reencontro com a pedagogia do oprimido. Rio de Janeiro: Paz e Terra, 1992.

FREIRE, P. Pedagogia da autonomia: saberes necessários à prática educativa. $12^{\circ}$ ed. São Paulo: Paz e Terra, 1999.

GARCIA, M. M. A. O intelectual educacional e o professor críticos: o pastorado das consciências. Currículo sem Fronteiras. V. 2,. N. 2. p. 53-78, jul./dez. 2002a.

GARCIA, M. M. A. Pedagogias críticas e subjetivação: uma perspectiva foucaultiana. Petrópolis: Vozes, 2002b.

HOFFMAN, J. Avaliação mito e desafio. Porto Alegre: Mediação, 1991.

LARROSA, J. Tecnologias do Eu e Educação. In: SILVA, T. T. da (org.). O sujeito da educação: estudos foucaultianos. $4^{\circ}$ ed. Petrópolis: Vozes, 2000, p. 35-86.

KAFKA, F. Durante a Construção da Muralha da China. In: KAFKA, F. Narrativas do espólio (1914-1924). Organização de Modesto Carone. São Paulo: Companhia das Letras, 2002a.

KAFKA, F. Investigações de um Cão. In: KAFKA, F. Narrativas do espólio (19141924). Organização de Modesto Carone. São Paulo: Companhia das Letras, 2002b.

MATOS, S. R. da L. Didática e suas forças vertiginosas. Conjectura. Caxias do Sul, v. 14, n. 1, p. 93-134, jan./mai. 2009.

MORAES, A. L.; VEIGA-NETO, A. Disciplina e controle na escola: do aluno dócil ao aluno flexível. In: Anais do IV Colóquio Luso-Brasileiro sobre Questões Curriculares. Florianópolis: UFSC, 2008, p. 1-18.

NIETZSCHE, F. A genealogia da moral. Uma polêmica. Trad. Paulo César de Souza. São Paulo: Companhia das Letras, 1998.

NIETZSCHE, F. A vontade de poder. Trad. Marcos Sinésio Pereira Fernandes e Francisco José Dias de Moraes. Rio de Janeiro: Contraponto, 2008.

NOGUERA-RAMÍREZ, C. E. Pedagogia e governamentalidade: ou Da Modernidade como uma sociedade educativa. Belo Horizonte: Autêntica, 2011 (Coleção Estudos Foucaultianos).

SILVA, T. T. Documentos de Identidade. Uma introdução às teorias do currículo. Belo Horizonte: Autêntica, 1999.

VASCONCELOS, C. Construção de conhecimento em sala de aula. São Paulo: Libertat, 1993. 
VEIGA-NETO, A. Currículo: um desvio à direita ou Delírios Avaliatórios. In: Anais do X Colóquio sobre Questões Curriculares e VI Colóquio Luso-Brasileiro de Currículo. Belo Horizonte: UFMG, 2012, p. 1-17.

WALKERDINE, V. Uma análise foucaultiana da pedagogia construtivista. In: SILVA, T. T. da (org.). Liberdades Reguladas: a pedagogia construtivista e outras formas de governo do eu. $2^{\circ}$ ed. Petrópolis: Vozes, 1999, p. 143-216.

Recebido em: 02 de janeiro de 2018 Aprovado em: 10 de setembro de 2018 